\title{
A Parametric Evaluation of Flexural and Tensile Strength Ratios, and Bundle Stresses of Axial Composites Using Weibull's Theory
}

\author{
Mohammed Faruqi, Ankur Patel \\ Department of Civil and Architectural Engineering, Texas A \& M University - Kingsville, Kingsville, USA
}

\section{Email address:}

m-faruqi@tamuk.edu (M. Faruqi)

\section{To cite this article:}

Mohammed Faruqi, Ankur Patel. A Parametric Evaluation of Flexural and Tensile Strength Ratios, and Bundle Stresses of Axial Composites Using Weibull's Theory. Engineering and Applied Sciences. Vol. 2, No. 6, 2017, pp. 99-102. doi: 10.11648/j.eas.20170206.11

Received: September 12, 2017; Accepted: November 8, 2017; Published: December 22, 2017

\begin{abstract}
Weibull theory works well for brittle materials. However, its application to composites is not very clear. The present study is a comparative parametric evaluation of flexural and tensile strength ratios, and fiber bundle stresses of axial composites with brittle fiber bundles. A composite based model that utilizes Weibull's theory is developed and compared with derived Weibull's theory for brittle fiber bundles. It was found that the predicted strength ratios and the stresses are of similar magnitude to that of Weibull's and the model converges to unity for composite materials with little or no variability.
\end{abstract}

Keywords: Axial Composites, Weibull Theory, Flexural Strength, Tensile Strength

\section{Introduction}

Carbon composites are used in many applications such as in beam design, aircraft, helicopter rotor blades and fishing rods $[1,2]$. They have the ability to resist high amount of damage before failure [3]. According to Tsai [4] unidirectional composites with higher stiffness have lower strength in tension than bending and the stiffness is controlled by stress-strain relationship. Tension, flexure, and combination of both are of considerable practical interest in predicting the tensile and flexural strength of composites.

Whitney and Knight [5] calculated strength ratio within the range of 1.03 to 1.33 for tension and bending tests. Bullock [6] performed a three point test and obtained ratios within 1.35 to 1.50 . As per Weibull statistical strength theory, strength is higher in bending than tension [7]. This can be attributed to the fact that in a bending test, a smaller value of material is subjected to stress as oppose to tension test. The probability of critical defect is lower and there-fore the strength is higher. The probability $\mathrm{P}$ of two parameter Weibull model is provided by:

$$
P=e^{\left[-\int\left(\frac{S}{s_{o}}\right) w d v\right]}
$$

Where $\mathrm{P}, \mathrm{S}, \mathrm{S}_{\mathrm{o}}, \mathrm{w}$, e and $\mathrm{dv}$ are respectively survival probability, strength, specific strength, Weibull modulus, exponent and specific volume under stress [6]. Weibull theory works well for brittle materials, but its application to composite materials is less clear.

Recently [8] research work was carried out to evaluate the tensile, and flexural strength of hybrid composites using experimental work and Finite Element Analysis (FEM). The outcome indicated that the hybrid composites improved strength.

Development and characterization [9] of natural fiber based composites consisting of jute fiber as reinforcement and hybrid resin consisting of general purpose resin and cashew nut shell resin as matrix material. The tensile strength was studied using experiment-al and numerical analysis.

Tensile behavior of environment friendly jute epoxy laminated composite was experimentally studied [10]. It was found that the tensile properties of the developed composites were strongly dependent on the tensile strength of jute fibers. In addition, jute fibers are very much defect sensitive.

Unidirectional composites [11] were fabrica-fabricated in laboratory using compression molding. It was found that by increasing the molding temperature, the achievement ratio of tensile strength was decreased due to deterioration of jute fiber.

Strength prediction of composite components subjected to 
tension, flexure, or a combination of both are of considerable practical interest. However, most of the work has been either experimental, numerical or a combination of both. These tend to be expensive. Therefore,

this study makes a basic first attempt to parametrically study the flexural and tensile strength ratios, and bundle stresses of axial composites with brittle fiber bundles.

\section{Description of Model}

The individual elements are assumed to split under tension and act independently. Their strength is assumed to follow Weibull distribution. All the symbols used in the model are listed in the notation section.

\section{Derivation of Proposed Model}

Survival probability of fiber under strain is:

$$
\mathrm{P}=\mathrm{e}^{\left[-\mathrm{L}\left(\varepsilon / \varepsilon_{0}\right)\right] \mathrm{w}}
$$

Consider tension in the fiber direction of a unidirectional composite. It is assumed that tensile strain is responsible for failure in a bundle that carries the maximum amount of stress. The nominal stress of bundle is equivalent to individual element stress multiplied by fraction of remaining fibers. This provides:

$$
\mathrm{S}=\varepsilon E P
$$

Where, E is equal for all fibers. Substituting values from equation (2) into equation (3) provides:

$$
\mathrm{S}=\varepsilon \mathrm{Ee}^{\left[-\mathrm{L}\left(\varepsilon / \varepsilon_{0}\right)\right] \mathrm{w}}
$$

Maximum load carried by bundle is known as failure stress. Up to failure stress, a bundle can support a load while it suddenly fails in brittle materials. The maximum failure strain in tension of a bundle can be obtained by first derivative of nominal stress with respect to strain and equating it to zero. This provides:

$$
\mathrm{dS} / \mathrm{d} \varepsilon=\varepsilon \mathrm{E} \mathrm{e}^{\left[-\mathrm{L}\left(\varepsilon / \varepsilon_{\mathrm{o}}\right)\right] \mathrm{w}} \mathrm{d} \varepsilon
$$

Taking the derivative of equation (5) and equating it to

$$
\begin{gathered}
\mathrm{F}_{\mathrm{c}}=\int_{\varepsilon_{\mathrm{c}}}^{0}(\mathrm{w})^{-1 / \mathrm{w}}\left(\varepsilon_{\mathrm{t}}-\varepsilon_{\mathrm{c}}\right) \mathrm{n}^{2} \mathrm{dn}+\int_{0}^{\varepsilon_{\mathrm{t}}}(\mathrm{w})^{-1 / \mathrm{w}}\left(\varepsilon_{\mathrm{t}}-\varepsilon_{\mathrm{c}}\right) \mathrm{n}^{2} \mathrm{dn} \\
\mathrm{F}_{\mathrm{c}}=(\mathrm{w})^{-1 / \mathrm{w}}\left(\varepsilon_{\mathrm{t}}-\varepsilon_{\mathrm{c}}\right) \int_{\varepsilon_{\mathrm{c}}}^{0} \mathrm{n}^{2} \mathrm{dn}+(\mathrm{w})^{-1 / \mathrm{w}}\left(\varepsilon_{\mathrm{t}}-\varepsilon_{\mathrm{c}}\right) \int_{0}^{\varepsilon_{\mathrm{t}}} \mathrm{n}^{2} \mathrm{dn} \\
\mathrm{F}_{\mathrm{c}}=(\mathrm{w})^{-1 / \mathrm{w}}\left(\varepsilon_{\mathrm{t}}-\varepsilon_{\mathrm{c}}\right)\left[\mathrm{n}^{3} / 3\right]_{\varepsilon_{\mathrm{c}}}^{0}+(\mathrm{w})^{-1 / \mathrm{w}}\left(\varepsilon_{\mathrm{t}}-\varepsilon_{\mathrm{c}}\right) \int_{0}^{\varepsilon_{\mathrm{t}}} \mathrm{n}^{2} \mathrm{dn}
\end{gathered}
$$

Failure occurs in tension part. For compression purposes the value of strain in compression part can be taken as one. Therefore,

$$
\begin{gathered}
(w)^{-1 / w}\left(\varepsilon_{t}-\varepsilon_{c}\right)=1 \\
\mathrm{~F}_{\mathrm{c}}=-\varepsilon_{\mathrm{c}}{ }^{3} / 3+(\mathrm{w})^{-1 / \mathrm{w}}\left(\varepsilon_{\mathrm{t}}-\varepsilon_{\mathrm{c}}\right) \int_{0}^{\varepsilon_{\mathrm{t}}} \mathrm{n}^{2} \mathrm{dn}
\end{gathered}
$$

This yields as:

$$
\mathrm{F}_{\mathrm{c}}=\left(\varepsilon_{\mathrm{t}}-\varepsilon_{\mathrm{c}}\right)(\mathrm{w})^{-1 / \mathrm{w}} \int_{0}^{\varepsilon_{\mathrm{t}}} \mathrm{n}^{2} \mathrm{dn}-\varepsilon_{\mathrm{c}}^{3} / 3
$$

Axial force $A_{f}$ is zero $=>$ pure bending moment. Therefore,

$$
\mathrm{A}_{\mathrm{f}}=\int \varepsilon \mathrm{E} \varepsilon_{0}(\mathrm{w})^{-1 / \mathrm{w}} \mathrm{ndn}
$$


For $A_{\mathrm{f}}$ we don't need to multiply strain with neutral axis distance, so strain produced is $\left(\varepsilon_{\mathrm{t}}-\varepsilon_{\mathrm{c}}\right)$. Therefore,

$$
A_{f}=\int E \varepsilon_{0}\left(\varepsilon_{t}-\varepsilon_{c}\right)(w)^{-1 / w} n d n
$$

Limits are same as $\mathrm{F}_{\mathrm{c}}$, Young's modulus, and specific strain are taken as one. This yields,

$$
A_{f}=\int_{\varepsilon_{c}}^{0}(w)^{-1 / w}\left(\varepsilon_{t}-\varepsilon_{c}\right) n d n+\int_{0}^{\varepsilon_{t}}(w)^{-1 / w}\left(\varepsilon_{t}-\varepsilon_{c}\right) n d n
$$

Simplifying equation (23) yields:

$$
A_{f}=\left(\varepsilon_{t}-\varepsilon_{c}\right)(w)^{-1 / w} \int_{0}^{\varepsilon_{t}} n d n-\varepsilon_{c}^{2} / 2
$$

In a bundle, the tension portion is considered to have the same size fibers. Figure 1 shows different segments and strain profile.

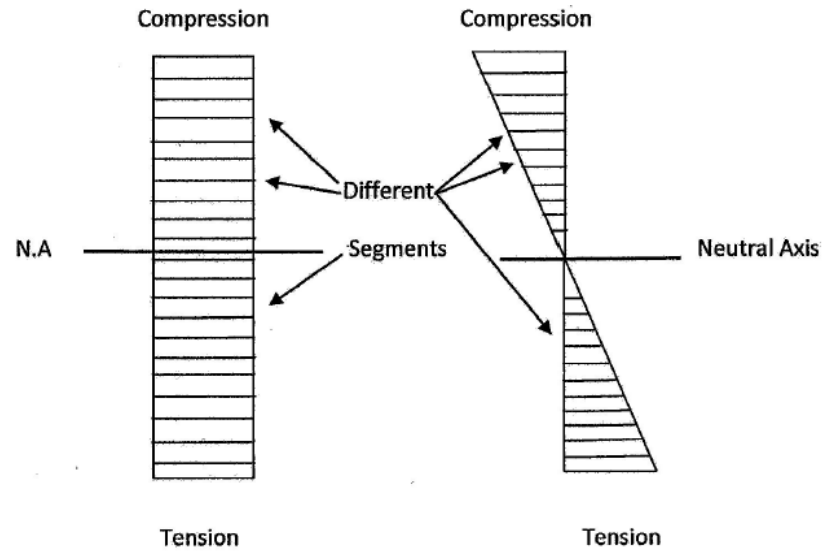

Figure 1. Segments and Strain Profile.

A solution from equation (24) is acquired as follows: Initially $\varepsilon_{\mathrm{c}}$ value is assumed. A trial and error method is adopted to calculate and iterate values of $\varepsilon_{\mathrm{t}}$ that provides zero axial force from equation (24). Strain values that provide maximum flexural capacity are considered failure strain in bending. The whole problem was repeated a number of times with increasing values of $\varepsilon_{\mathrm{c}}$ and the corresponding $\varepsilon_{\mathrm{t}}$ at which the maximum flexural capacity occurred is determined.

For values of $\varepsilon_{t}=\varepsilon_{c}$, we obtain $A_{f}$ as approximately zero. This means the system is in pure bending. Taking the ratio of $\varepsilon_{\mathrm{t}}$ and equation (10) provides:

$$
\frac{\varepsilon_{t}}{\varepsilon_{0}(w)^{-\frac{1}{w}}}
$$

Considering $\varepsilon_{0}$ and $\varepsilon_{\mathrm{t}}$ as one provides:

$$
\text { Bending to tension ratio }=(w)^{\frac{1}{w}}
$$

\section{Derivation of Weibull's Ratios for Brittle Fiber Bundles}

Equation (2) provides the survival probability $(\mathrm{P})$ of fibers under strain $(\varepsilon)$ using Weibull's theory. Therefore, failure strain distribution can be (1-P). Using the survival probability, strength in brittle fiber bundle can be calculated. The average failure strain $\left(\mathrm{S}_{\mathrm{f}}\right)$ in brittle fiber bundle is:

$$
\mathrm{S}_{\mathrm{f}}=\int_{0}^{\infty} \varepsilon\left(-\frac{\mathrm{dP}}{\mathrm{d} \varepsilon}\right) \mathrm{d} \varepsilon
$$

This implies that

$$
\mathrm{S}_{\mathrm{f}}=\varepsilon_{0} \mathrm{~L}^{-1 / \mathrm{w}} \Gamma(1+1 / \mathrm{w})
$$

The average flexural stress $\sigma_{\mathrm{b}}$ in brittle fibers is:

$$
\begin{gathered}
\sigma_{\mathrm{b}}=\mathrm{S}_{\mathrm{f}} \mathrm{E} \\
\sigma_{\mathrm{b}}=\mathrm{E} \varepsilon_{0} \mathrm{~L}^{-1 / \mathrm{w}} \Gamma(1+1 / \mathrm{w})
\end{gathered}
$$

The expression in equation (10) is the maximum failure strain in tension of a composite bundle. However, in terms of stress for a unit length the same relation holds for maximum failure stress in tension. Therefore, the ratio of maximum failure stress in bending equation (30) and tension is:

$$
\begin{aligned}
& \frac{\sigma_{\mathrm{b}}}{\sigma_{\mathrm{t}}}=\frac{\mathrm{E} \varepsilon_{0} \mathrm{~L}^{-1 / \mathrm{w}} \Gamma(1+1 / \mathrm{w})}{\varepsilon_{0}(\mathrm{Lw})^{-1 / w}} \\
& \frac{\sigma_{\mathrm{b}}}{\sigma_{\mathrm{t}}}=\left(\frac{\mathrm{w}+1}{\mathrm{w}}\right) \mathrm{w}^{1 / \mathrm{w}}
\end{aligned}
$$

\section{Analytical Data}

Table 1 shows a comparison of bending to tension ratio of the developed composite model to Weibull's ratio for brittle fiber bund-le using equations (26) and (32) respectively. Table 2 shows a comparison of average bundle stress in composite fibers with average bundle stress in brittle fibers. These stresses are obtained using equations (4) and (30) respectively. For comparison purposes, various parameters are assumed to be one.

Table 1. Comparison of proposed model to Weibull's.

\begin{tabular}{llll}
\hline W & Proposed Model (p) & Weibull Model (WM) & p/WM \\
\hline 13 & 1.21 & 1.31 & 0.923 \\
18 & 1.15 & 1.24 & 0.927 \\
23 & 1.14 & 1.19 & 0.957 \\
28 & 1.12 & 1.16 & 0.966 \\
33 & 1.11 & 1.14 & 0.973 \\
38 & 1.09 & 1.12 & 0.973 \\
50 & 1.08 & 1.10 & 0.981 \\
\hline
\end{tabular}

Table 2. Comparison of Bundle stresses.

\begin{tabular}{lll}
\hline $\mathbf{W}$ & $\begin{array}{l}\text { Bundle stress in composite } \\
\text { fibers }\end{array}$ & $\begin{array}{l}\text { Bundle stress in a brittle } \\
\text { fibers }\end{array}$ \\
\hline 10 & 0.794 & 1.1 \\
20 & 0.860 & 1.05 \\
30 & 0.892 & 1.03 \\
40 & 0.911 & 1.025 \\
1000 & 0.99 & 1.00 \\
\hline
\end{tabular}

\section{Comparison of Ratios}

The results show that the proposed model has a higher strength in bending than in tension. The magnitude of the effect seems to be decreasing for higher Weibull modulus. 
The strength ratio for our model varies from 1.21 for $\mathrm{W}=13$ to 1.08 for $\mathrm{W}=50$. On the other hand, Weibull model predicts, 1.31 and 1.10 for respective $\mathrm{W}$ values. The ratios predicted by the proposed model are a bit conservative. In addition, for larger values of $\mathrm{W}$ the model converge to 1.0. This is indicative of a material with very little to no variation. A similar trend is observed for composite and brittle bundle fiber stresses.

\section{Conclusions}

Weibull theory works well with brittle materials. However, its application to composites is not clear.

The present study is a comparative parametric evaluation of flexural and tensile strength ratios, and fiber bundle stresses of axial composites with brittle fiber bundles. A composite fiber bundle model that applies Weibull theory is developed and compared with derived Weibull theory for brittle fiber bundles.

The following limited conclusions can be obtained from this work:

1. The predicted ratios and the stresses are of similar magnitude to that of Weibull's; and

2. At higher $\mathrm{W}$ values, the model converges to one.

\section{Future Work}

Good agreement is obtained between the models. However, more work is needed to further validate this approach. This may include:

1. Experimental work on materials of different variability; and

2. Comparison of experimental results with the model.

\section{Notations}

P Survival probability of fibers

$\mathrm{S} \quad$ Nominal bundle stress

$\mathrm{S}_{\mathrm{o}} \quad$ Specific strength

w Weibull modulus

L Length of fiber

E Young's modulus of fiber

$\varepsilon \quad$ Strain at a particular distance from neutral axis

$\varepsilon_{0} \quad$ Specific strain

$\varepsilon_{\mathrm{t}} \quad$ Maximum tensile strain

$\varepsilon_{\mathrm{c}} \quad$ Compressive strain

$\mathrm{t}$ Thickness

$\mathrm{S}_{\mathrm{b}} \quad$ Strength of bundle in bending

$\mathrm{F}_{\mathrm{c}} \quad$ Flexural capacity

$n$ Distance from neutral axis

$\mathrm{A}_{\mathrm{f}} \quad$ Axial force

$\mathrm{S}_{\mathrm{t}} \quad$ Strength of bundle in tension

$\mathrm{S}_{\mathrm{f}} \quad$ Failure strain in bundle
Г Gamma function

b Width of bundle

$\mathrm{dv} \quad$ First derivative with respect to volume

dS First derivative with respect to stress

$\mathrm{d} \varepsilon \quad$ First derivative with respect to strain

dn First derivative with respect to distance from neutral axis

$\sigma_{\mathrm{b}} \quad$ Maximum bundle stress in flexure

$\sigma_{\mathrm{t}} \quad$ Maximum bundle stress in tension

$\mathrm{p} \quad$ Proposed model

W Weibull model

\section{References}

[1] Wisnom, M. R., (1992), "The Relation-ship between Tensile and Flexural Strength of Unidirectional Composite-s", The Journal of Composite Materials, Vol. 26 (8), pp 1173-1180.

[2] Brent, A. S., (1989), "Fundamentals of Composites Manufacturing", $5^{\text {th }}$ ed, Society of Manufacturing Engineers, pp 5-20.

[3] Wisnom, M. R., (1991), "Relationship between Strength Variability and Size effect in Unidirectional Carbon fiber/epoxy", The Journal of Composites, Vol. 22 (1), pp 4751.

[4] Tsai, S. W., (1980), "Introduction to Composite Materials", 1st edn, Technical Publishing Company Inc., pp 360-390.

[5] Whitney, J. M., \& Knight M., (1980), "The Relationship between Tensile strength and Flexural strength in FiberReinforced Composites", Experimental mechanics, Vol. 20 (6), pp 211-216.

[6] Bullock, R. E., (1974), "Strength Ratio of Composite materials in Flexural and in Tension", The Journal of Composite Materials, Vol. 8 (2), pp 200-206.

[7] Weibull, W., (1951), "Statistical Distribution Function of Wide Applicability", Journal of Applied Mechanics, Vol. 18, pp 293-297.

[8] Ashik K P et al., (2017), "Evaluation of tensile, flexural and impact strength of natural and glass fiber reinforced hybrid composites", Renewable Bioresources, ISSN 2052- 6237, Vol 5 (1). http://dx.doi.org/10.7243/2052-6237-5-1.

[9] Vishnu P et al., (2014), "Finite Element Analysis of Jute and Banana Fibre Reinforced Hybrid Polymer Matrix Composite and Optimization of Design Parameters Using ANOVA Technique", Procedia Engineering, Vol 97, pp 1116-1125.

[10] Hossain et al., (2013), "Tensile Behavior of Environment Friendly Jute Epoxy Laminated Composite", Procedia Engineering, Vol 56, pp 782-788.

[11] Anin, M., \& Asami, N., (2013), "Fabrication and Mechanical Properties of Jute Spun Yarn/PLA Unidirectional Composite by Compression Molding", Energy Procedia, Vol 34, pp 840838 . 